\title{
Timeliness and completeness of routine childhood vaccinations in young children residing in a district with recurrent vaccine-preventable disease outbreaks, Jerusalem, Israel
}

\section{Chen Stein-Zamir ${ }^{1,2}$, Avi Israeli3,4}

1. The Hebrew University of Jerusalem, Faculty of medicine, the Hebrew University and Hadassah Braun School of Public health and Community Medicine, Jerusalem, Israel

2. Jerusalem District Health Office, Ministry of Health, Jerusalem, Israel

3. The Hebrew University of Jerusalem, Faculty of medicine, the Hebrew University and Hadassah Braun School of Public health and Community Medicine, Department of Health Policy and Management, Jerusalem, Israel

4. Chief Scientist, Ministry of Health, Jerusalem, Israel

Correspondence: Chen Stein-Zamir (chen.zamir@mail.huji.ac.il)

Citation style for this article:

Stein-Zamir Chen, Israeli Avi. Timeliness and completeness of routine childhood vaccinations in young children residing in a district with recurrent vaccinepreventable disease outbreaks, Jerusalem, Israel. Euro Surveill. 2019;24(6):pii=1800004. https://doi.org/10.2807/1560-7917.ES.2019.24.1800004

Background: Childhood vaccination schedules recommend vaccine doses at predefined ages. Aim: We evaluated vaccination completeness and timeliness in Jerusalem, a district with recurrent vaccine-preventable disease outbreaks. Methods: Vaccination coverage was monitored by the up-to-date method (vaccination completeness at age 2 years). Timeliness of vaccination was assessed in children $(n=3,098$, born in 2009, followed to age 48 months, re-evaluated at age 7 years) by the age-appropriate method (vaccine dose timeliness according to recommended schedule). Vaccines included: hepatitis B (HBV: birth, 1 month and 6 months); diphtheria, tetanus, acellular pertussis, polio, Haemophilus influenzae b (DTaP-IPV-Hib: 2, 4, 6 and 12 months); pneumococcal conjugate (PCV: 2, 4 and 12 months); measles-mumps-rubella/measlesmumps-rubella-varicella (MMR/MMRV: 12 months) and hepatitis A (HAV: 18 and 24 months). Results: Overall vaccination coverage $(2014$ cohort evaluated at age 2 years) was $95 \%$ and $86 \%$ for MMR/MMRV and DTaPIPV-Hib4, respectively. Most children (94\%, 91\%, 79\%, $95 \%, 92 \%$ and $82 \%$ ) were up-to-date for $\mathrm{HBV}_{3}$, DTaPIPV-Hib4, PCV $3, M M R / M M R V_{1}, H_{1} V_{1}$ and HAV2 vaccines at 48 months, but only $32 \%, 28 \%, 38 \%, 58 \%$, $49 \%$ and $20 \%$ were vaccinated timely (age-appropriate). At age 7 years, the median increase in vaccination coverage was $2.4 \%$. Vaccination delay was associated with: high birth order, ethnicity (higher among Jews vs Arabs), birth in winter, delayed acceptance of first dose of DTaP-IPV-Hib and multiple-dose vaccines (vs MMR/ MMRV). Jewish ultra-Orthodox communities had low vaccination coverage. Conclusions: Considerable vaccination delay should be addressed within the vaccine hesitancy spectrum. Delays may induce susceptibility to vaccine-preventable disease outbreaks; tailored programmes to improve timeliness are required.

\section{Background}

Vaccines have contributed to substantial reductions of morbidity and mortality from vaccine-preventable diseases (VPD), mainly in children. Vaccinations avert 2-3 million deaths annually; if global vaccination coverage improves, another 1.5 million deaths are preventable [1]. The estimated global coverage for the first dose of measles-containing vaccine (MCV1) and for diphtheriatetanus-pertussis (DTP3) was 82\% for both in 2009 and $85 \%$ and $86 \%$, respectively, in 2014 ; this is below the Global Vaccine Action Plan (GVAP) targets of $90 \%$ nationally and $80 \%$ in all districts [2]. For measles, the recommended coverage is higher, at $95 \%$ or more across all districts and age groups [3].

Routine vaccinations in Israel are included in the National Health Insurance Law. Community-based maternal and child health $(\mathrm{MCH})$ clinics provide free vaccination to children regardless of civil status, with high rates $(96 \%)$ of service utilisation $[4,5]$. Vaccine doses are documented in digital health files. The overall vaccination coverage rates reported in Israel are adequate (at age 2 years in 2016: DTaP-IPV-Hib4 at $94 \%, \mathrm{HBV}_{3}$ at $97 \%$ and MMR/MMRV 1 at 96\%) with all districts well in line with World Health Organization (WHO) goals $[6,7]$. Yet, VPD outbreaks observed in specific communities (Arab Bedouin in southern Israel and Jewish ultra-Orthodox in Jerusalem) revealed underimmunised population groups [8-10]. 
Incidence of selected notifiable vaccine-preventable diseases ${ }^{\mathrm{a}}$ and reported overall mean coverage of selected routine childhood vaccinations ${ }^{\mathrm{b}}$, Jerusalem district, Israel, 2000-2016

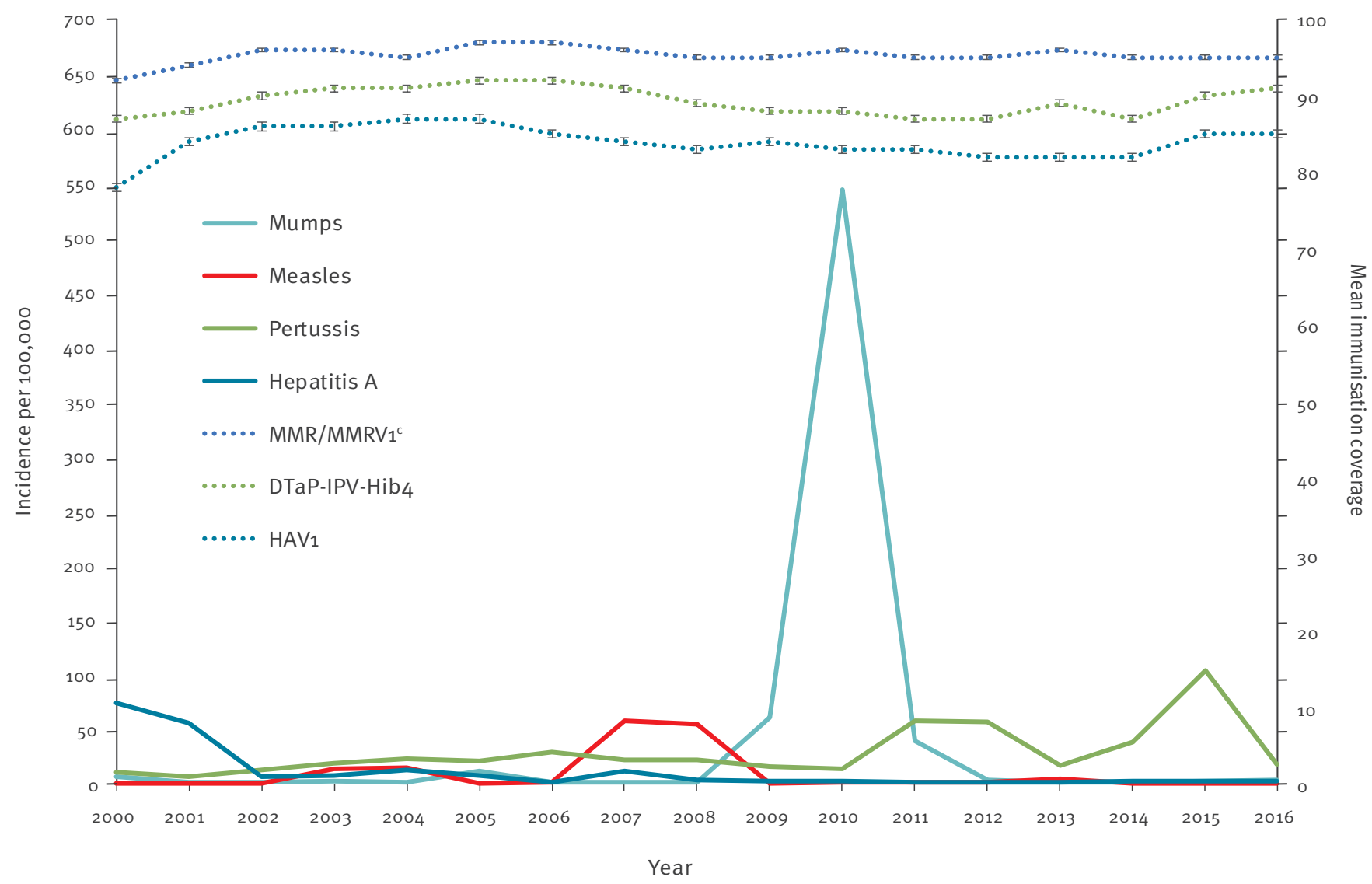

DTaP-IPV-Hib4: diphtheria, tetanus, acellular pertussis, polio, Haemophilus influenzae b vaccine, fourth dose; HAV1: hepatitis A vaccine, first dose; MMR/MMRV1: measles-mumps-rubella/measles-mumps-rubella-varicella vaccine, first dose.

a Incidence per 100,000 population of measles, mumps, pertussis and hepatitis A.

${ }^{b} M M R / M M R V_{1}$, DTaP-IPV-Hib4 and HAV1, as up-to-date at age 2 years (vaccination completeness).

${ }^{\mathrm{c}}$ MMRV vaccine replaced MMR in 2008.

In the last two decades, several VPD outbreaks emerged in the Jerusalem district (Figure 1). Measles and mumps outbreaks emerged mainly in Jewish ultraOrthodox communities, with epidemiological links to similar communities in Europe and the United States (US) [10-13]. The district health office's teams perform surveillance, epidemiological investigations and outbreak control activities; community-wide vaccination campaigns led to outbreaks' containment, with remarkable population compliance during the campaigns.

Recurrent VPD outbreaks indicated the need for a detailed assessment of vaccination coverage in the affected district. Our study evaluated timeliness and completeness of routine childhood vaccinations in order to identify factors associated with vaccination receipt patterns and to gather information for planning public health intervention programmes.

\section{Methods}

\section{Setting and study population}

The Jerusalem district's population increased from 1 to 1.2 million between 2009 and 2016 (30\% Arabs and $70 \%$ Jews; about $40 \%$ of the Jews are ultra-Orthodox). Neighbourhoods in the area are homogenous, with Arab, Jewish ultra-Orthodox and Jewish traditionalsecular residents. The socioeconomic status of the district's population is medium to low. The district's total fertility rate is four (Jewish ultra-Orthodox: 6.2-6.5), compared with three nationally. Children under 6 years comprise $15 \%$ of the district's population $[14,15]$.

The study group for detailed vaccine acceptance evaluation included children born in 2009 in the Jerusalem district. The sample size was calculated taking the 
TABLE

General characteristics of the study group, children born in 2009 and followed up to 7 years of age, Jerusalem district, Israel, $2016(\mathrm{n}=3,098)$

\begin{tabular}{|c|c|c|}
\hline Variables & $n^{a}=3,098$ & $\%$ \\
\hline Male & 1,571 & 50.7 \\
\hline Birth weight (g), mean \pm SD & $3,245 \pm 528$ & NA \\
\hline Birth weight $<2,500 \mathrm{~g}$ & 257 & 8.3 \\
\hline Birth order, mean \pm SD & $3.4 \pm 2.4$ & NA \\
\hline Birth order, median (range) & $3(1-14)$ & NA \\
\hline Birth order $\geq 4$ & 1,151 & 37.2 \\
\hline $\begin{array}{l}\text { Mother's age (years), } \\
\text { mean } \pm \text { SD }\end{array}$ & $29.1 \pm 6$ & NA \\
\hline $\begin{array}{l}\text { Mother's age (years), } \\
\text { median (range) }\end{array}$ & $28(15-55)$ & NA \\
\hline $\begin{array}{l}\text { Mother's birth country is } \\
\text { Israel }\end{array}$ & 2,506 & 80.9 \\
\hline Mother's status is married & 3,009 & 97.1 \\
\hline $\begin{array}{l}\text { Maternal education (years), } \\
\text { mean } \pm \text { SD }\end{array}$ & $13 \cdot 7 \pm 2.4$ & NA \\
\hline $\begin{array}{l}\text { Maternal education, median } \\
\text { (range) }\end{array}$ & $14(4-23)$ & NA \\
\hline Ethnicity: Jewish/Arab & $2,163 / 935$ & $70 / 30$ \\
\hline \multicolumn{3}{|l|}{ Month of birth } \\
\hline January-March & 722 & $23 \cdot 3$ \\
\hline April-June & 762 & 24.6 \\
\hline July-September & 818 & 26.4 \\
\hline October-December & 796 & 25.7 \\
\hline
\end{tabular}

g: grams; NA: not applicable; SD: standard deviation.

a Unless otherwise specified.

following into account: unvaccinated fraction (5-25\%), $1.5 \%$ precision and a $95 \%$ confidence interval $(\mathrm{Cl})$. Post adjustment, the study group was selected from the district's newborns file using the Statistical Package for Social Sciences (SPSS) software v23.o (IBM, New York, US) random sampling of data procedure $(n=3,180$ children, $10.7 \%$ of the 29,700 live births registered in the district in 2009). The inclusion criteria were: born in Israel, has a unique identifier (identification (ID) number allowing data matching) and survived 48 months. The exclusion criteria were: born abroad (different schedules), lacks a unique identifier and did not survive 48 months.

\section{Variables collected}

The general variables collected included the child's date of birth, sex, ethnicity, address, birth order and birthweight, as well as the mother's age, country of birth and marital status.

\section{Vaccination variables}

The Jerusalem district routine vaccination coverage is monitored by data aggregation in the up-to-date method (vaccination completeness, Figure 1). The upto-date method does not reflect vaccination timeliness, which is better assessed by the age-appropriate method (indicating the child's age at specific vaccine doses). The launch of a national immunisation registry in 2009 enabled appraisal of both completeness and timeliness.

The scheduled immunisations included: hepatitis B vaccine (HBV: at birth, 1 month and 6 months); diphtheria, tetanus, acellular pertussis, polio, Haemophilus influenzae b vaccine (DTaP-IPV-Hib: at 2, 4, 6 and 12 months); pneumococcal conjugate vaccine (PCV: at 2, 4 and 12 months); measles-mumps-rubella/measlesmumps-rubella-varicella vaccine (MMR/MMRV: at 12 months) and hepatitis A vaccine (HAV: at 18 and 24 months). MMRV vaccine replaced MMR in 2008 and $P C V$ vaccine was introduced in 2009.

Vaccine doses were defined as valid according to the Israel Ministry of Health $(\mathrm{MoH})$ guidelines for minimum ages and time intervals between doses. Vaccine doses received up to 1 month after the recommended age were considered timely (no delay). The children's ID numbers and dates of birth were cross-checked against the vaccination registry and vaccination data were extracted. After data assembly, records were available for 3,098/3,180 (97\%) of the children. The groups of children with available records and those with missing records had similar birthweight, sex, birth order and maternal variables.

The vaccination data were evaluated at age 24 months (2011) and age 48 months (2013), then re-evaluated at age 7 years (2016). For the present study's purposes, the following categories were defined according to the child's vaccination status: (i) age-appropriate (vaccinated at the recommended age or $\leq 1$ month later), (ii) mild-moderate delay (delayed $\leq 6$ months; mild: $>1$ month and $\leq 3$ months, moderate: $>3$ months and $\leq 6$ months) (iii) severe delay (delayed 6 months) and (iv) unvaccinated (at 48 months).

\section{Data analysis}

Data analysis was performed with SPSS software v23.0. The age-specific immunisation coverage was retrieved from a cumulative fraction of vaccinated children by age and plotted in inverse Kaplan-Meier curves (survival analysis curves). Days of vaccination delay were converted into months as 30.5 days/month. $A$ univariate analysis was performed for each vaccine $\left(\mathrm{HBV}_{3}, \mathrm{DTaP}-\mathrm{IPV}-\mathrm{Hib}_{4}, \mathrm{PCV}_{3}, \mathrm{MMR} / \mathrm{MMRV} \mathrm{V}_{1}, \mathrm{HAV}_{1}\right.$ and HAV2) exploring child and maternal characteristics for association with vaccination timeliness. Variables with statistical significance at $p$ value $<0.05$ were included in the multivariate analysis. A multiple regression analysis model was performed for general variables associated with a child's vaccination status being up-to-date. Associations between the variables and vaccination status are presented as odds ratio (OR) and $95 \% \mathrm{Cl}$. A $p$ value of $<0.05$ was considered significant for all comparisons. 
The cumulative proportion of vaccine uptake by child's age in months using the inverse Kaplan-Meier curves for selected vaccine doses ${ }^{a}$, in children born in 2009 and followed up to 7 years of age, Jerusalem district, Israel, $2016(\mathrm{n}=3,098)$

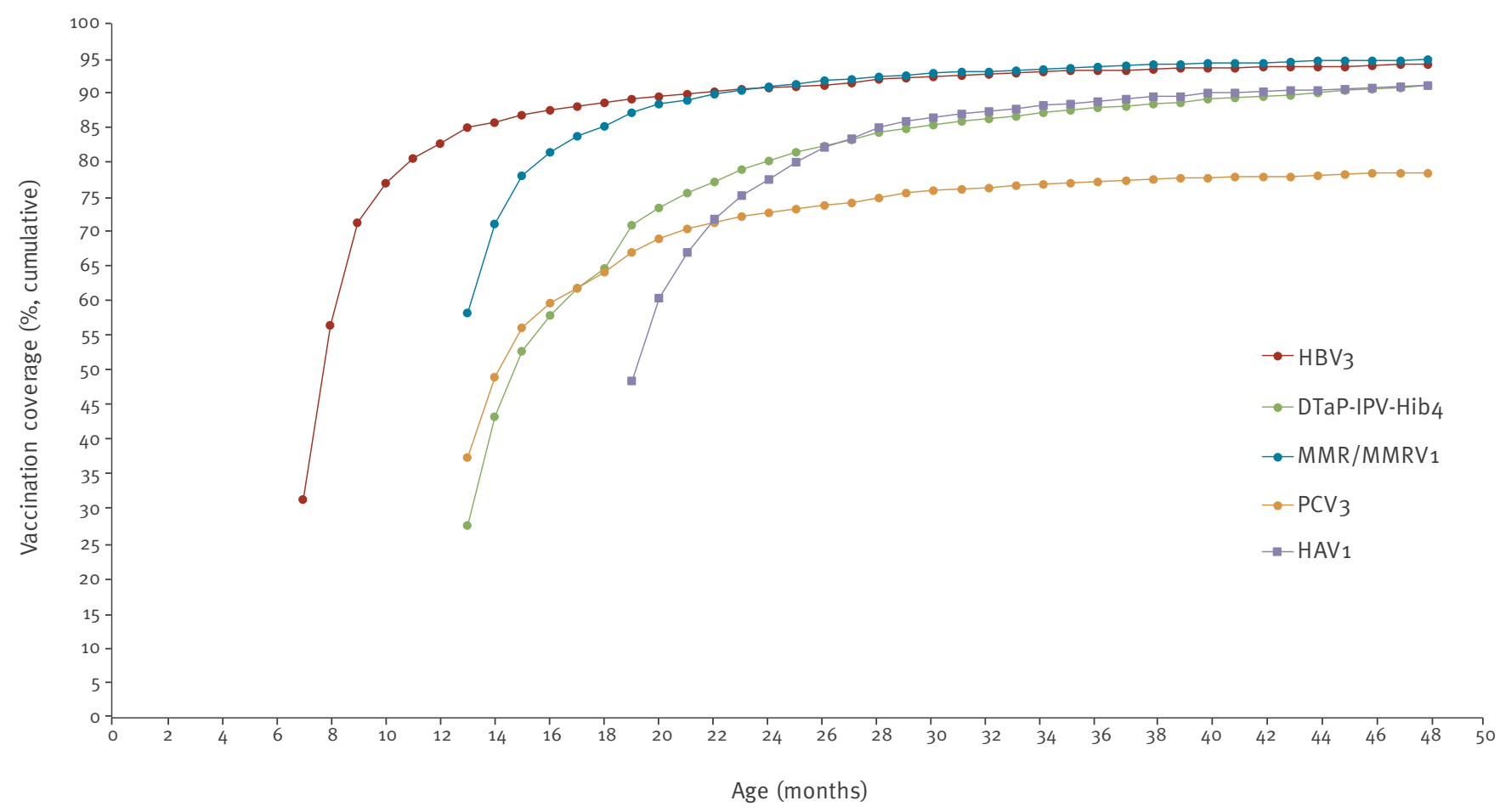

DTaP-IPV-Hib4: diphtheria, tetanus, acellular pertussis, polio, Haemophilus influenzae b vaccine, fourth dose; HAV1: hepatitis A vaccine, first dose; $\mathrm{HBV}_{3}$ : hepatitis $\mathrm{B}$ vaccine, third dose; MMR/MMRV1: measles-mumps-rubella/measles-mumps-rubella-varicella vaccine, first dose; PCV3: pneumococcal conjugate vaccine, third dose.

a DTaP-IPV-Hib4 is scheduled at 12 months, HAV1 at 18 months, HBV 3 at 6 months, MMR/MMRV1 at 12 months (MMRV vaccine replaced MMR in 2008) and PCV3 at 12 months.

\section{Ethical approval}

This study was approved by the Israel $\mathrm{MoH}$ Institutional Review Board and was conducted according to the relevant $\mathrm{MoH}$ instructions. All collected data were treated as confidential, in strict compliance of legislation on observational studies.

\section{Results}

The general characteristics of the 3,098 children born in the Jerusalem district in 2009 and their mothers are presented in Table 1. Half of them (50.7\%) were male. The cumulative fraction of vaccine uptake by inverse Kaplan-Meier curves for HBV3, DTaP-IPV-Hib4, MMR/ $M M R V_{1}, \mathrm{PCV}_{3}$ and $\mathrm{HAV}_{1}$ are presented in Figure 2. The age-specific rates at three points in time were as follows: for $\mathrm{HBV}_{3}, 31.5 \%, 82.8 \%$ and $90.8 \%$ were vaccinated at 7,12 and 24 months, respectively. For DTaP-IPV-Hib4, 27.7\%, 64.8\% and $80.2 \%$ at 13,18 and 24 months. For $\mathrm{PCV}_{3}, 37.6 \%, 64.1 \%$ and $72.6 \%$ at age 13,18 and 24 months. For MMR/MMRV1, 58.3\%, 85.2\% and $90.8 \%$ at 13,18 and 24 months. For HAV 1 , at 19 and 24 months, $48.6 \%$ and $78 \%$.
The distribution by vaccination categories at age 48 months (Figure 3) showed that, depending on the vaccine, between $82-95 \%$ of the children were defined as vaccinated up-to-date. The up-to-date rates for the HBV 3 , DTaP-IPV-Hib4, PCV $3, M M R / M M R V_{1}, \mathrm{HAV}_{1}$ and $\mathrm{HAV}_{2}$ vaccine doses were 94\%, 91\%, 79\%, 95\%, $92 \%$ and $82 \%$, respectively. The age-specific vaccination rates showed that only $32 \%, 28 \%, 38 \%, 58 \%$, $49 \%$ and $20 \%$ of children were defined as age-appropriate for these vaccine doses. The fraction of severe delay was higher in the multiple-dose vaccines $(26 \%$ for DTaP-IPV-Hib4, 22\% for HAV2) compared with $10 \%$ for $M M R / M M R V_{1}$. The fraction of children defined as unvaccinated at 48 months also ranged between $18 \%$ for $\mathrm{HAV}_{2}, 21 \%$ for $\mathrm{PCV}_{3}$ (in the cohort year of introduction into the schedule) and $5-9 \%$ for the other vaccine doses.

The cumulative fraction of vaccine uptake among children in the three main population groups-Arab, Jewish ultra-Orthodox and Jewish traditional-secularfor DTaP-IPV-Hib4 and MMR/MMRV1 are presented in Figure 4. Vaccination completeness and timeliness were higher in Arab children compared to Jewish 


\section{FIGURE 3}

Distribution of vaccination coverage by defined categories (status at the age of 48 months) for selected vaccine doses, in children born in 2009, Jerusalem district, Israel, 2016 $(\mathrm{n}=3,098)$
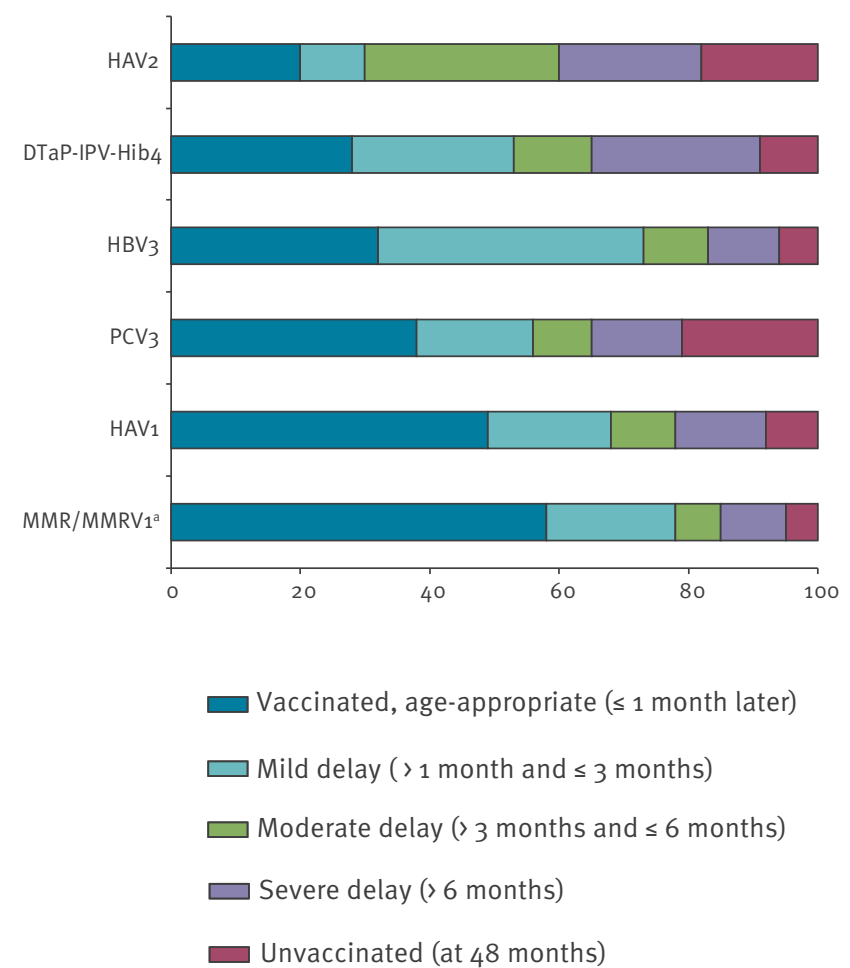

DTaP-IPV-Hib4: diphtheria, tetanus, acellular pertussis, polio, Haemophilus influenzae b vaccine, fourth dose; HAV1: hepatitis $A$ vaccine, first dose; $\mathrm{HAV}_{2}$ : hepatitis $A$ vaccine, second dose; $\mathrm{HBV}_{3}$ : hepatitis $B$ vaccine, third dose; MMR/MMRV 1 : measles mumps-rubella/measles-mumps-rubella-varicella vaccine, first dose; $\mathrm{PCV}_{3}$ : pneumococcal conjugate vaccine, third dose.

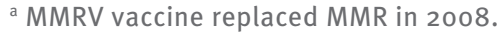

children, with the lowest rates among children in Jewish ultra-Orthodox communities.

Multiple logistic regression analysis with the dependent variable 'vaccinated up-to-date' at age 24 months and the study group general variables was performed (Supplement S1). The up-to-date vaccination status defined for age 24 months included the vaccine doses $\mathrm{HBV}_{3}, \mathrm{DTaP}-\mathrm{IPV}-\mathrm{Hib}_{4}, \mathrm{PCV}_{3}$ and MMR/MMRV1. The variables that were significantly associated with vaccination delay were: high birth order, ethnicity (higher among Jews vs Arabs), birth in winter (January-March) and delayed receipt of the first dose of DTaP-IPV-Hib vaccine scheduled at age two months (OR:4.67; 95\% Cl: $3.72-5.87$ ).

A re-evaluation of vaccination status was carried out for the study group children at the age of 7 years. The vaccination coverage rates showed some increase for all the evaluated vaccine doses: $\mathrm{HBV}_{3}(1.7 \%)$, DTaPIPV 4 (3.1\%), PCV 3 (1\%), MMR/MMRV 1 (1.2\%) and HAV 2
(8\%). The median increase observed in vaccination coverage rates was $2.4 \%$.

\section{Discussion}

The overall childhood vaccination coverage reported in Israel is consistently high $[6,7]$. While aggregated vaccination rates are high, disaggregated data reveal gaps amid population groups $[4,8,16]$. Vaccinations gaps and delays, despite appropriate up-to-date coverage, have been reported from developed and developing countries [17-25]. Hence, accurate monitoring of vaccination coverage and timeliness is essential $[9,21,26]$. The up-to-date vaccination coverage rates were all over $90 \%$ for the vaccines evaluated in our study; ageappropriate rates were lower. A similar percentage of children were in the categories 'mild-moderate delay' and 'age-appropriate' for multiple-dose vaccines. The MMR/MMRV1 vaccine was less delayed, perhaps because its application does not depend on the timing of a previous dose and because efforts are made to ensure timeliness to prevent outbreaks. The 7 -valent pneumococcal conjugate vaccine $\left(\mathrm{PCV}_{7}\right)$ was included into the routine schedule in 2009 and $\mathrm{PCV}_{13}$ replaced $\mathrm{PCV}_{7}$ in 2010 [27]. The coverage rate for the third dose of PCV in our group was lower than the $91 \%$ national rate [4]. Mothers in the Jerusalem district reported declining 'new' vaccines (e.g. PCV) more often [28]. The reasons for this are unclear and may be attributed to the provision and promotion of new vaccines.

The association between social determinants and health outcomes has been well established [29]. A medium to low socioeconomic status and a high proportion of children in the Jerusalem district have been linked to the spread of communicable disease $[10,13]$. Delayed vaccinations were associated with a child's birth order, ethnicity, season of birth and delayed receipt of the first dose of the DTaP-IPV-Hib vaccine. The median child's birth order was third in Jerusalem, compared with second nationally, with $37 \%$ of children born fourth and above. A high birth order has been associated with vaccination delay $[18,21-25]$. Vaccination completeness and timeliness were higher in Arab children compared to Jewish children in Jerusalem, which is similar to data for the country overall $[4,16]$. In a polio vaccine campaign in Israel (2013), the compliance was higher in the Arab than in the Jewish population [30]. Birth in the winter months was also associated with childhood vaccination delay. Delays, most of which are unnecessary, are often related to acute respiratory infections during winter [28]. Parents may perceive delaying vaccination as a safer alternative to the routine childhood vaccination schedules [31]. In our group, delayed receipt of the first dose of the DTaP-IPV-Hib vaccine was highly associated with not being up-to-date at 24 and 48 months. In a US survey, children with delayed vaccines at 3 months had significantly lower up-to-date coverage (at 19-35 months) compared to children without early delay [32]. In a study among Jewish ultra-Orthodox mothers in Israel, infant vaccination receipt at age 2 months was highly predictive for later adherence to 
The cumulative proportion of vaccination uptake by age for (A) DTaP-IPV-Hib4 and (B) MMR/MMRV1 ${ }^{\text {a }}$, in children born in 2009 and followed up to 7 years of age, by main population groups, Jerusalem district, Israel $2016(\mathrm{n}=3,098)$

\section{A. DTaP-IPV-Hib4}

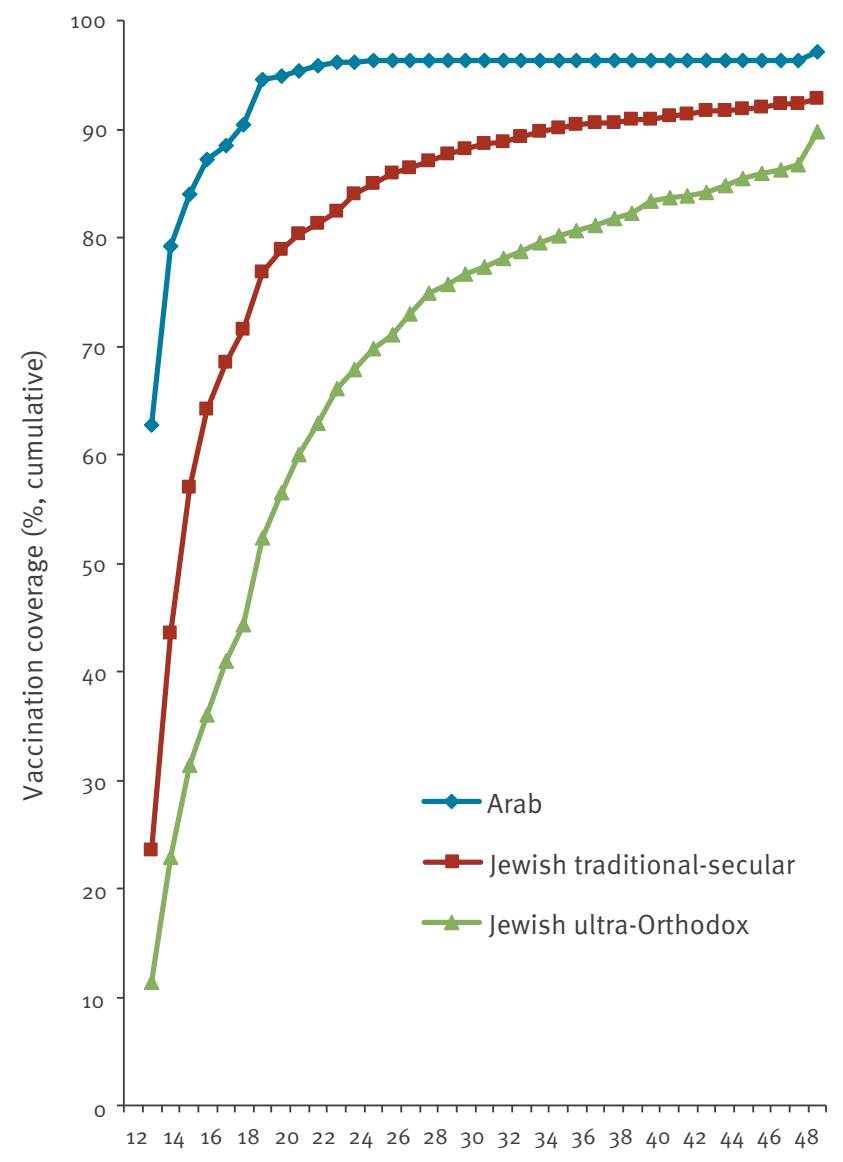

Age (months)

\section{B. MMR/MMRV1}

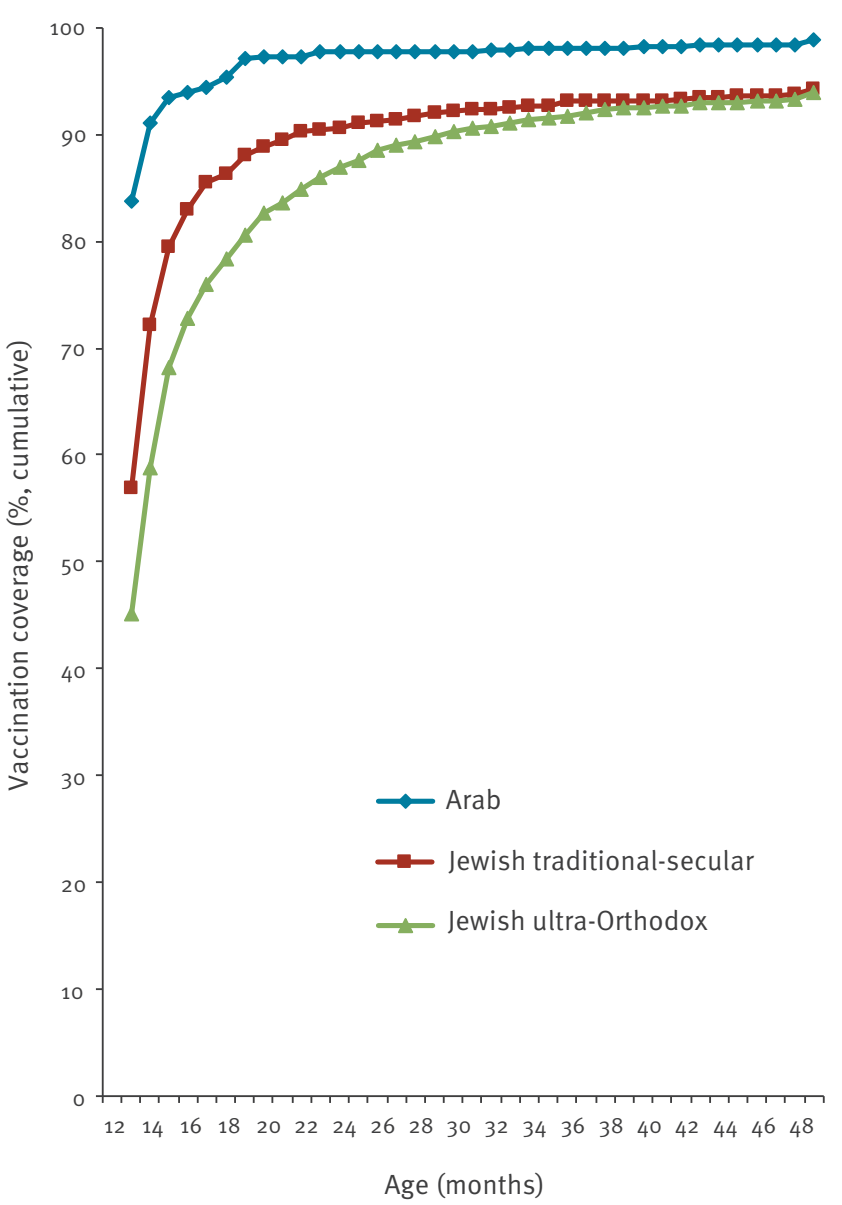

DTaP-IPV-Hib4: diphtheria, tetanus, acellular pertussis, polio, Haemophilus influenzae b vaccine, fourth dose; MMR/MMRV1: measles-mumpsrubella/measles-mumps-rubella-varicella vaccine, first dose.

${ }^{\mathrm{a}} \mathrm{MMRV}$ vaccine replaced MMR in 2008.

the schedule [33]. Children in Jewish ultra-Orthodox communities were found at risk for delayed and missing vaccinations $[10,13]$, as in these communities delay was not perceived as affecting a child's health [28].

The results of this study are subject to limitations. Only children with full data were included and this may have led to an underestimate of vaccine delay. However, counting documented vaccine doses was the only way to obtain accurate vaccination dates. Yet, even the digital records may have been incomplete, with some dates not registered, resulting in an overestimate of vaccine delay. Children who left the area or died were also excluded; therefore, there may be a bias in estimates of the cumulative proportion of vaccination. As for factors affecting vaccination receipt, we included mainly sociodemographic factors. We were unable to include health-related parameters or factors related to the performance of the preventive health services supplier, which should be further evaluated.

After the completion of our study, from March to December 2018, measles importation to Israel resulted in spread to unvaccinated persons, with some 3,150 notified cases (https://www.health.gov.il/English/ Topics/Pregnancy/Vaccination_of_infants/Pages/measles.aspx). The outbreak reached Jerusalem in late August 2018 and at present some 1,800 cases have been notified in Jerusalem; $82 \%(1,470)$ are children under 15 years of age who almost exclusively reside in ultra-Orthodox Jewish neighbourhoods. An 18-monthold toddler died in Jerusalem in November 2018 and in December 2018 an 82-year-old woman in Jerusalem became the second fatality from the outbreak. The child's death was the first recorded death from measles in Israel in 15 years 
The recent outbreak and our findings denote the importance of accurate vaccination data for detecting risk groups, reducing missed opportunities and planning tailored immunisation programmes. Vaccination delay is a common phenomenon that may induce pockets of susceptible populations to VPD outbreaks; therefore, it should be adequately addressed within the vaccine hesitancy spectrum. Vaccine hesitancy refers to the delay in acceptance or refusal of vaccines despite availability of vaccination services. It includes factors such as complacency, convenience and confidence [34]. It has been estimated that $7.5-9 \%$ of Israeli parents deviate from the routine vaccination schedule mostly as a consequence of parental decision [35,36]. While most Israeli parents (90\%) reported that they had fully immunised their children, the confidence in official recommendations declined from $87 \%$ in 2008 to $72 \%$ in 2016 [37]. Addressing various forms of vaccine hesitancy is an increasingly complex challenge for health professionals $[34,38]$. The preventive framework should combine vaccination plans with health promotion measures, the most effective of which are multi-component $[34,39]$. Particularly in areas and communities with suboptimal vaccine uptake (as found in our study), efforts and budget allocations should prioritise investments that support availability, accessibility and appropriateness of preventive services for children [40]. Implementation of systematic supplementary immunization activities (SIAs) such as mass vaccination campaigns is still essential while the current preventive services are being strengthened [41]. The integration of multiple vaccination-related activities will hopefully further reduce the burden of vaccinepreventable diseases in children.

\section{Acknowledgements}

The authors wish to acknowledge Dr. Nitza Abramson MD MPH and Hanna Shoob MPH from the Jerusalem district health office; Ziona Haklai MA, head of Health Information Division, Ministry of health; Nesia Cohen, Information technology, Ministry of health; Dr. Mario Baras, Braun School of Public and Community Medicine, Hebrew university of Jerusalem; and Prof Itamar Grotto, Head of Public Health Services, Ministry of health, Jerusalem Israel. The authors would like to acknowledge the dedicated public health nurses and physicians in the Mother and Child health clinics in the Jerusalem district, Israel.

\section{Conflict of interest}

None declared.

\section{Authors' contributions}

The conception and design of the study were formed by Chen Stein-Zamir and Avi Israeli. The study was approved by the Israel Ministry of Health Institutional Review Board and conducted according to the relevant Ministry of Health instructions. Data assembly, analysis, interpretation and final approval of the manuscript were performed by Chen SteinZamir and Avi Israeli.

\section{References}

1. World Health Organization (WHO). Immunization coverage Geneva: WHO; 2018. Available from: http://www.who.int/ mediacentre/factsheets/fs378/en/

2. Subaiya S, Dumolard L, Lydon P, Gacic-Dobo M, Eggers R, Conklin LCenters for Disease Control and Prevention (CDC). Global routine vaccination coverage, 2014. MMWR Morb Mortal Wkly Rep. 2015;64(44):1252-5. https://doi.org/10.15585/ mmwr.mm6444a5 PMID: 26562454

3. World Health Organization (WHO). Global Vaccine Action Plan. Geneva: WHO; 2015. Available from: http://www.who.int/ immunization/global_vaccine_action_plan/gvap_secretariat_ report_2015.pdf?ua $=1$

4. Rubin L, Belmaker I, Somekh E, Urkin J, Rudolf M, Honovich M, et al. Maternal and child health in Israel: building lives. Lancet. 2017;389(10088):2514-30. https://doi.org/10.1016/S01406736(17)30929-7 PMID: 28495101

5. Tasher D, Rubin L, Grossman Z, Grotto I, Dahan D, Berlowitz Y, et al. Child Health Care in Israel. J Pediatr. 2016;177:S107-15. https://doi.org/10.1016/j.jpeds.2016.04.047 PMID: 27666258

6. World Health Organization (WHO). Israel: WHO and UNICEF estimates of immunization coverage: 2017 revision. Geneva: WHO; 2017. Available from: http://www.who.int/immunization/ monitoring surveillance/data/isr.pdf

7. Israel Central Bureau of Statistics (CBS). Statistical Abstract of Israel 2018, No.69. Children immunized out of those registered in the mother and infant centers. Jerusalem: CBS; 2018. Available from: https://www.cbs.gov.il/he/publications/ doclib/2018/6.\%20shnatonhealth/sto6_12.pdf

8. Belmaker I, Dukhan L, Elgrici M, Yosef Y, Shahar-Rotberg L. Reduction of vaccine-preventable communicable diseases in a Bedouin population: summary of a community-based intervention programme. Lancet. 2006;367(9515):987-91. https://doi.org/10.1016/S0140-6736(06)68425-0 PMID: 16564360

9. Papania M, Rodewald L. For better immunisation coverage, measure coverage better. Lancet. 2006;367(9515):9656. https://doi.org/10.1016/S0140-6736(06)68403-1 PMID: 16564344

10. Stein-Zamir C, Abramson N, Shoob H, Zentner G. An outbreak of measles in an ultra-orthodox Jewish community in Jerusalem, Israel, 2007--an in-depth report. Euro Surveill. 2008;13(8):8045. PMID: 18445412

11. Stein-Zamir C, Shoob H, Abramson N, Tallen-Gozani E, Sokolov I, Zentner G. Mumps outbreak in Jerusalem affecting mainly male adolescents. Euro Surveill. 2009;14(50):19440. PMID: 20070937

12. Muscat $M$. Who gets measles in Europe? J Infect Dis. 2011;204(Suppl 1):S353-65. https://doi.org/10.1093/infdis/ jiro67 PMID: 21666185

13. Muhsen K, Abed El-Hai R, Amit-Aharon A, Nehama H, Gondia $M$, Davidovitch $N$, et al. Risk factors of underutilization of childhood immunizations in ultraorthodox Jewish communities in Israel despite high access to health care services. Vaccine. 2012;30(12):2109-15. https://doi.org/10.1016/j. vaccine.2012.01.044 PMID: 22285273

14. Israel Central Bureau of Statistics (CBS). Statistical Abstract of Israel 2018, No.69. Population, by population group, religion, age and sex, district and sub-district. Jerusalem: CBS; 2018. Available from: https://www.cbs.gov.il/he/publications/ doclib/2018/2.\%20shnatonpopulation/sto2_19x.pdf

15. Choshen M, Korach M, Doron I, Israeli Y, Assaf-Shapira Y. Jerusalem: Facts and Trends 2013. Jerusalem: The Jerusalem Institute for Israel Studies; 2013. Available from: http:// en.jerusaleminstitute.org.il/.upload/facts-2013-eng\%20(1).pdf

16. Israel National Council for the Child (NCC) and the Bernard van Leer Foundation. The State of Young Children in Israel 2015. Jerusalem and The Hague: The Israel National Council for the Child and the Bernard van Leer Foundation; 2015. Available from: https://bernardvanleer.org/app/uploads/2016/03/TheState-of-Young-Children-in-Israel-2015_hi-res.pdf

17. Clark A, Sanderson C. Timing of children's vaccinations in 45 low-income and middle-income countries: an analysis of survey data. Lancet. 2009;373(9674):1543-9. https://doi.org/10.1016/ S0140-6736(09)60317-2 PMID: 19303633

18. Lernout T, Theeten H, Hens N, Braeckman T, Roelants M, Hoppenbrouwers $\mathrm{K}$, et al. Timeliness of infant vaccination and factors related with delay in Flanders, Belgium. Vaccine. 2014;32(2):284-9. https://doi.org/10.1016/j. vaccine.2013.10.084 PMID: 24252698 
19. Hu Y, Chen Y, Guo J, Tang X, Shen L. Completeness and timeliness of vaccination and determinants for low and late uptake among young children in eastern China. Hum Vaccin Immunother. 2014;10(5):1408-15. https://doi.org/10.4161/ hv. 28054 PMID: 24584000

20. Rieck T, Feig M, Eckmanns T, Benzler J, Siedler A, Wichmann 0 . Vaccination coverage among children in Germany estimated by analysis of health insurance claims data. Hum Vaccin Immunother. 2014;10(2):476-84. https://doi.org/10.4161/ hv.26986 PMID: 24192604

21. Dayan GH, Shaw KM, Baughman AL, Orellana LC, Forlenza $R$, Ellis $A$, et al. Assessment of delay in age-appropriate vaccination using survival analysis. Am J Epidemiol. 2006;163(6):561-70. https://doi.org/10.1093/aje/kwj074 PMID: 16421238

22. Akmatov MK, Mikolajczyk RT. Timeliness of childhood vaccinations in 31 low and middle-income countries. J Epidemiol Community Health. 2012;66(7):e14. https://doi. org/10.1136/jech.2010.124651 PMID: 21551179

23. Luman ET, Barker LE, Shaw KM, McCauley MM, Buehler JW, Pickering LK. Timeliness of childhood vaccinations in the United States: days undervaccinated and number of vaccines delayed. JAMA. 2005;293(10):1204-11. https://doi.org/10.1001/ jama.293.10.1204 PMID: 15755943

24. Dombkowski KJ, Lantz PM, Freed GL. Risk factors for delay in age-appropriate vaccination. Public Health Rep. 2004;119(2):144-55. https://doi. org/10.1177/003335490411900207 PMID: 15192901

25. Pavlopoulou ID, Michail KA, Samoli E, Tsiftis G, Tsoumakas K. Immunization coverage and predictive factors for complete and age-appropriate vaccination among preschoolers in Athens, Greece: a cross--sectional study. BMC Public Health. 2013;13(1):908. https://doi.org/10.1186/1471-2458-13-908 PMID: 24083352

26. Johansen K, Lopalco PL, Giesecke J. Immunisation registers-important for vaccinated individuals, vaccinators and public health. Euro Surveill. 2012;17(16):20151. PMID: 22551460

27. Ben-Shimol S, Greenberg D, Givon-Lavi N, Schlesinger Y, Somekh E, Aviner S, et al. Early impact of sequential introduction of 7 -valent and 13-valent pneumococcal conjugate vaccine on IPD in Israeli children 45 years: an active prospective nationwide surveillance. Vaccine. 2014;32(27):3452-9. https:// doi.org/10.1016/j.vaccine.2014.03.065 PMID: 24690148

28. Stein Zamir C, Israeli A. Knowledge, Attitudes and Perceptions About Routine Childhood Vaccinations Among Jewish Ultra-Orthodox Mothers Residing in Communities with Low Vaccination Coverage in the Jerusalem District. Matern Child Health J. 2017;21(5):1010-7. https://doi.org/10.1007/s10995017-2272-5 PMID: 28093690

29. Marmot M. Social determinants of health inequalities. Lancet. 2005;365(9464):1099-104. https://doi.org/10.1016/S01406736(05)74234-3 PMID: 15781105

30. Binyaminy B, Bilenko N, Haas EJ, Grotto I, Gdalevich M. Socioeconomic status and vaccine coverage during wild-type poliovirus emergence in Israel. Epidemiol Infect. 2016;144(13):2840-7. https://doi.org/10.1017/ So950268816000844 PMID: 27141821

31. Dempsey AF, Schaffer S, Singer D, Butchart A, Davis M, Freed GL. Alternative vaccination schedule preferences among parents of young children. Pediatrics. 2011;128(5):848-56. https://doi.org/10.1542/peds.2011-0400 PMID: 21969290

32. Rosenthal J, Rodewald L, McCauley M, Berman S, Irigoyen M, Sawyer M, et al. Immunization coverage levels among 19- to 35-month-old children in 4 diverse, medically underserved areas of the United States. Pediatrics. 2004;113(4):e296-302. https://doi.org/10.1542/peds.113.4.e296 PMID: 15060256

33. Simhi M, Shraga Y, Sarid O. Vaccination of Infants and Health Beliefs of Ultra Orthodox Mothers. J Vaccines Vaccin. 2013;5(1):213.

34. World Health Organization (WHO). Addressing Vaccine Hesitancy. Geneva: WHO; 2018. Available from: http:// www.who.int/immunization/programmes_systems/ vaccine_hesitancy/en/

35. Velan B. Vaccine hesitancy as self-determination: an Israeli perspective. Isr J Health Policy Res. 2016;5(1):13. https://doi. org/10.1186/s13584-016-0071-x PMID: 27051517

36. Amit Aharon A, Nehama H, Rishpon S, Baron-Epel O. A path analysis model suggesting the association between health locus of control and compliance with childhood vaccinations. Hum Vaccin Immunother. 2018;14(7):1618-25. https://doi.org/1 $0.1080 / 21645515 \cdot 2018.1471305$ PMID: 29771633

37. Grossman Z, Hadjipanayis A, Degani A, Somekh E. Tracking Changes in Vaccine Attitudes and Decisions: Results from 2008 and 2016 Parental Surveys. Pediatr Infect Dis J. 2018;1. PMID: 30001230
38. Grossman Z, Ashkenazi S, Rubin L. How are we responding to vaccine-hesitant parents? Lancet Child Adolesc Health. 2017;1(1):9-11. https://doi.org/10.1016/S2352-4642(17)300408 PMID: 30169232

39. Centers for Disease Control and Prevention (CDC). A CDC framework for preventing infectious diseases. Atlanta: CDC; 2011. Available from: https://www.cdc.gov/oid/docs/IDFramework.pdf

40. Fournet N, Mollema L, Ruijs WL, Harmsen IA, Keck F, Durand $\mathrm{JY}$, et al. Under-vaccinated groups in Europe and their beliefs, attitudes and reasons for non-vaccination; two systematic reviews. BMC Public Health. 2018;18(1):196. https://doi. org/10.1186/s12889-018-5103-8 PMID: 29378545

41. Orenstein WA, Hinman A, Nkowane B, Olive JM, Reingold A. Measles and Rubella Global Strategic Plan 2012-2020 midterm review. Vaccine. 2018;36(Suppl 1):A1-34. https://doi. org/10.1016/j.vaccine.2017.09.026 PMID: 29307367

\section{License and copyright}

This is an open-access article distributed under the terms of the Creative Commons Attribution (CC BY 4.0) Licence. You may share and adapt the material, but must give appropriate credit to the source, provide a link to the licence, and indicate if changes were made.

This article is copyright of the authors or their affiliated institutions, 2019. 